\title{
Assessment of Socioeconomic status and the Prevalence of Tungiasis in Jimma and Wolaita sodo, Ethiopia
}

Suresh Kumar. P. Nair ${ }^{* 1}$, Zelalem .T. L ${ }^{1}$, Tsehayneh. K ${ }^{1}$, Mehidi. $K^{1}$, Vidhya Ramaswamy V ${ }^{2}$.

${ }^{* 1}$ Department of Biomedical Sciences, College of Public Health and Medical Sciences, JIM MA University, Ethiopia.

${ }^{2}$ INCITE, Sri Rams, N. H. Road, Kazhakuttom, Trivandrum- 695 582, Kerala, India.

\section{ABSTRACT}

Background: Morbidity profile of parasitic diseases reflects the socioeconomic conditions of a population. This study was conducted to reveal the socio-economic status and prevalence of tungiasis in different villages of south and south western Ethiopia. Tungiasis is a parasitic skin disease caused by a flea called Tunga penetrans and is endemic in Latin American and Sub-Saharan African countries.

Aim: To study the socioeconomic presentations and prevalence of tungiasis in rural and urban settings of different villages of Ethiopia.

Methods: A cross-sectional study was conducted among randomly selected people, using a standard questionnaire with interview and clinical evaluation. The team visited the selected subjects and studied the socio-economic issues and affecting the prevalence of Tungiasis.

Results: 2676 subjects were studied. Response rate was $100 \%$. The prevalence of tungiasis was $15.15 \%$ in Jimma and $23.9 \%$ in Wolaita sodo. High prevalence of tungiasis could be significantly associated with the low income, poor housing and low standard living conditions and poor health care behavior of the population ( $p$ value $\ll .001)$.

Conclusions: This study elicits the link between low socioeconomic conditions of the population with high prevalence of the disease in the communities studied.

KEY WORDS: Tungiasis, Inflammation, Erythemic, Desquamation, Parasitic disease.

Address for correspondence: Dr. Suresh Kumar. P. Nair, Department of Biomedical Sciences, College of Public Health and M edical Sciences, JIM M A University, Ethiopia.

E-Mail: sureshkumarpnair@gmail.com

\begin{tabular}{|c|c|c|}
\hline \multicolumn{3}{|c|}{ Online Access and Article Informtaion } \\
\hline  & $\begin{array}{r}\text { International Jour } \\
\text { wu }\end{array}$ & $\begin{array}{l}\text { ntegrative Medical Sciences } \\
\text { sciences.com }\end{array}$ \\
\hline 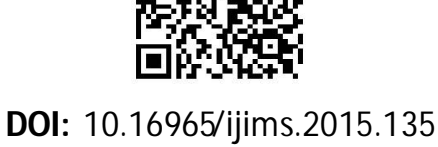 & $\begin{array}{l}\text { Received: 09-11-2015 } \\
\text { Revision: 20-11-2015 }\end{array}$ & $\begin{array}{l}\text { Accepted: 18-01-2016 } \\
\text { Published: 31-01-2016 }\end{array}$ \\
\hline
\end{tabular}

\section{INTRODUCTION}

Tungiasis or mujali is a parasitic disease of skin caused by a female flea Tunga penetrans. This ectoparasitic skin disease was endemic in economically backward communities of South America and Africa [1-3]. Gonzalo Fernandez de Oviels in 1526 reported first time and was followed by European travelers in South American population $[2,4]$. This disease came to Africa probably in $1873[1,5]$. Symptoms of the disease are inflammation of the skin at the area of entrance of the flea, followed by severe itching with a black dot at the centre and a white space around the black dot often accompanied by severe pain. The hyper growth of the flea results in desquamation of the epithelium. The removal of the flea using thorns or unsterilized needle may results in infections in the area (Plate VI). 
Plate I: Tungiasis leisions with egg.

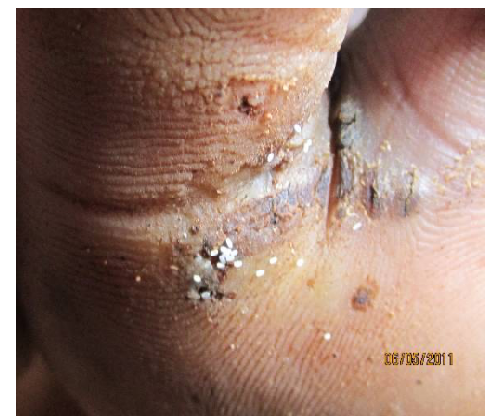

Photo IV: Deformed nails of a two year old child.

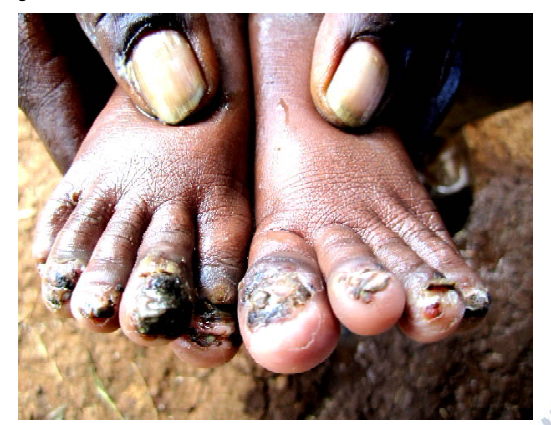

This disease affects human and animals [6-8]. As this disease affects both human and animal, close contact of the animals increases the chance of infection $[8,9]$. Tunga penetrans complete its life cycle in the sandy or muddy floor of the houses and it premises. So poor houses with muddy or sandy soil, unhygienic health behavior of the population, all these factors affects the rate of infection [10-12]. Previous studies revealed that there were high prevalence of disease in sheep, dog and pig $[8,13,14]$.

Tunga penetrans penetrate in to the skin and within 24 hours cause severe pain and within 2,3 days the afflicted area become inflammatory and erythemic with severe itching. Female flea only need animal or human host and within 8 to 12 days it become adult and hypertrophied. Plate-II shows the hypertrophied area of infection. Fleas get accommodated within the host body for 4 to 5 weeks and produce around 200 eggs $[3,15,16]$. Plate-I shows tungias leisions with eggs. Hyper growth of the flea results in irritation and cause redness and desquamation of the epithelium. Plate V and VI shows multiple sites of infection. Some times Tunga penetrans cause severe infection with multiple sites even exceeds 100. Plate III and IV shows deformed nails. Multiple lesions of toes may lead to deformation and auto amputation.
Plate III: Deformed nails due to tungiasis.

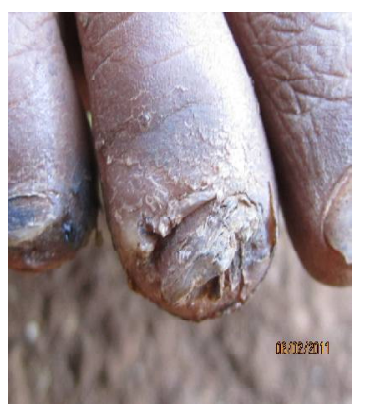

Plate VI: Tungaisis all over the foot.

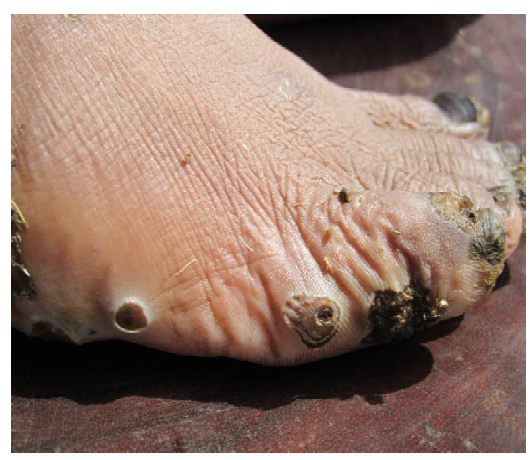

\section{MATERIALS AND METHODS}

This study was conducted among two separate Districts of Ethiopia, Wolaita sodo and Jimma, situated far apart each other and one is in the southern region of Ethiopia and other in south western region of Ethiopia. Jimma is the largest city in south west of Ethiopia. Located in the Jimma Zone of the Oromia region, the city has a latitude and longitude of $704^{\prime} \mathrm{N} 36^{\circ} 50^{\prime} \mathrm{E}$. It is $356 \mathrm{kms}$ far from Addis Ababa and has an altitude of 1760 meters above the sea level with mean annual rain fall of $17 \mathrm{~mm}$ throughout the year and the annual temperature range is between $10^{\circ} \mathrm{C}-30^{\circ} \mathrm{c}$. Wolaitta soddo is $390 \mathrm{Kms}$ away from the capital Addis Ababa, Southern part of Ethiopia. Wolaita sodo is located at latitude of $80^{\circ} 50^{\prime} \mathrm{N}$ and longitude of $37^{\circ} 5145^{\prime} \mathrm{E}$. The altitude ranges from $1100-2500$ m.a.s.l. This is one of the 13 zones in Southern Ethiopia. Some part of Wolaita soddo is situated in the rift valley and temperature varies from 20 to 42 degree centigrade.

A cross sectional study was conducted in different kebeles of these districts. The kebeles were selected by lottery method. All kebeles included in the study were located in high altitude except one kebele in Wolaita sodo, the Bedeso kebele which was located in a rift valley. The sample size of the study population was 
calculated using the formula $n=\frac{N^{2} P_{q}}{d^{2}(N-1)+z^{2} P c}$. From each kebele study subjects were selected randomly. Four kebeles from Wolaita sodo and four kebeles from jimma were selected by lottery method. The studied kebeles of Wolaita sodo were Delbo, Sora koyo (Bedessa), Gola and Hebre. Delbo, Sora koyo (Bedessa) represents Wolaita rural. Gola kebele and Hebre represents Wolaita sodo urban. Almeyehumecha and Bulbul belongs to Jimma rural. Bosa addis and Bosa kito were belongs to Jimma urban.

A stratified random sampling technique was adopted for kebeles with high population density. All households were selected from each kebele and a list of households in the kebele was prepared and a sample size of minimum 305 was selected by simple random sampling by using computer software. A standard questionnaire was developed using WHO questionnaire. Data was collected using the standard questionnaire by interviewing the selected subjects with clinical checkup. The base line characters and life style of the study population were studied. Participants or the parents of the participants ready to cooperate were clearly informed the importance of the study. Only those permanently inhabited in these places, between the age of 1 year to 75 and ready to sign the consent were included. People occasionally visiting other areas were excluded. The selected individual's clinical evaluation was conducted to reveal the severity of the infection [10].

The data collected were entered in computer daily and data were analyzed using frequency distribution, Fisher's exact test and Pearson Chi - square using SPSS version-20. Data is interpreted at $95 \%$ level of confidence. Ethical clearance was obtained from the Jimma University Ethical Committee.

\section{RESULTS}

This study covered households with a total population of 2676 distributed in eight different kebeles of two distant areas, Wolatia sodo situated in the southern part of Ethiopia and Jimma located in the south western part of Ethiopia. All kebeles included in this study were located in high altitude except one kebele in Wolaita sodo, the Bedeso kebele which is located in a rift valley. The studied community had a total population of 2676, out of which 1407(52.58\%) were female and 1269 were male $(47.42 \%)$. Annual income of the population is very low. In Wolaita sodo $97.28 \%$ of the population, annual income was only below 200 US dollar. In Jimma it was $90.25 \%$. This show that study population were economically backward. Literacy status of the rural communities of both Jimma and Wolata sodo were very low. In Wolaita $43.34 \%$ houses and in Jimma $58.64 \%$ houses were kacha type with sandy or muddy floorings. Many of the semi pucca houses were with sandy or muddy floorings. In Wolaita $88.88 \%$ houses were with muddy or sandy floorings, whereas in Jimma it was $68.54 \%$. Many of the houses were not electrified. Majority of the study groups were using foot wear.

In Wolaita sodo $23.9 \%$ were tungaisis positive where as in Jimma it was $15.1 \%$. Rural kebele shows a high prevalence of tungiasis compared to urban kebeles. Rift valley shows a low prevalence of tungiasis compared to high altitude population.

Table 1: Baseline characters of the population.

\begin{tabular}{|c|c|c|c|c|}
\hline \multirow{2}{*}{ Variable } & \multicolumn{2}{|c|}{$\begin{array}{c}\text { Wolaita sodo } \\
n=1322\end{array}$} & \multicolumn{2}{|c|}{$\begin{array}{l}\text { Jimma } \\
n=1354\end{array}$} \\
\hline & $\mathbf{n}$ & $\%$ & $\mathbf{n}$ & $\%$ \\
\hline \multicolumn{5}{|c|}{ Sex } \\
\hline Male & 621 & 46.97 & 648 & 47.85 \\
\hline me Female & 701 & 53.02 & 706 & 52.14 \\
\hline \multicolumn{5}{|c|}{ Literacy } \\
\hline Illiterate & 584 & 44.18 & 527 & 38.92 \\
\hline Read only & 82 & 6.2 & 18 & 1.33 \\
\hline 01-Jun & 508 & 38.43 & 560 & 41.36 \\
\hline 07-Dec & 144 & 10.89 & 216 & 15.95 \\
\hline$>12$ & 4 & 0.3 & 33 & 2.44 \\
\hline \multicolumn{5}{|c|}{ House type } \\
\hline Kacha & 573 & 43.34 & 794 & 58.64 \\
\hline Semi pucca & 741 & 56.05 & 539 & 39.81 \\
\hline Pucca & 8 & 0.61 & 21 & 1.56 \\
\hline \multicolumn{5}{|c|}{ Floor type } \\
\hline Sandy/muddy & 1175 & 88.88 & 928 & 68.54 \\
\hline Cemented & 147 & 11.12 & 417 & 30.78 \\
\hline \multicolumn{5}{|c|}{ Electrification } \\
\hline Electrified & 639 & 48.34 & 858 & 63.37 \\
\hline Not electrified & 683 & 51.66 & 496 & 36.63 \\
\hline \multicolumn{5}{|c|}{ Annual income } \\
\hline$<200 \$$ & 1286 & 97.28 & 1222 & 90.25 \\
\hline $201-500 \$$ & 36 & 2.72 & 127 & 9.38 \\
\hline $501-1000 \$$ & 0 & 0 & 5 & 0.37 \\
\hline$>1001 \$$ & 0 & 0 & 0 & 0 \\
\hline \multicolumn{5}{|c|}{ Footwear } \\
\hline Using & 991 & 74.96 & 1243 & 91.8 \\
\hline Not using & 331 & 25.04 & 111 & 8.2 \\
\hline
\end{tabular}


Suresh Kumar. P. Nair et al. Assessment of Socioeconomic status and the Prevalence of Tungiasis in Jimma and Wolaita sodo, Ethiopia.

Table 2: Shows the comparison of the prevalence of tungiasis in different study area.

\begin{tabular}{|c|c|c|c|c|c|c|}
\hline \multirow{2}{*}{ Area } & \multirow{2}{*}{$\mathbf{n}$} & \multicolumn{3}{|c|}{ tungiasis } & \multirow{2}{*}{ Chi square } & \multirow{2}{*}{ p value } \\
\cline { 3 - 5 } & & Neg & pos & $\%$ & & \\
\hline Wolaita & 1300 & 989 & 311 & 23.9 & \multirow{2}{*}{32.61} & \multirow{2}{*}{$0.001^{* * *}$} \\
\hline Jimma & 1342 & 1139 & 203 & 15.1 & & \\
\hline Jimma rural & 664 & 503 & 161 & 24.2 & \multirow{2}{*}{85.15} & \multirow{2}{*}{$0.001^{* * *}$} \\
\hline Jimma urban & 678 & 636 & 42 & 6.2 & & \multirow{2}{*}{0.058} \\
\hline Wolaita rural & 671 & 525 & 146 & 21.8 & \multirow{2}{*}{3.57} & \multirow{2}{*}{$0.001^{* * *}$} \\
\hline Wolaita urban & 629 & 464 & 165 & 26.2 & & \\
\hline High altitude & 419 & 278 & 141 & 33.7 & \multirow{2}{*}{92.69} & \\
\hline Rift valley & 252 & 247 & 5 & 2 & &
\end{tabular}

Table 3: Shows the association between socio-economic status and tungiasis.

\begin{tabular}{|c|c|c|c|c|}
\hline \multirow{3}{*}{ variables } & \multirow{2}{*}{\multicolumn{2}{|c|}{$\begin{array}{c}\begin{array}{c}\text { Total subjects } \\
\mathrm{n}=2676\end{array} \\
\text { Tungiasis } \\
\end{array}$}} & \multirow[t]{3}{*}{ Chi square } & \multirow[t]{2}{*}{$P$ value } \\
\hline & & & & \\
\hline & neg & pos & & \\
\hline \multicolumn{5}{|c|}{ Sex } \\
\hline Male & 1010 & 259 & \multirow{2}{*}{2.247} & \\
\hline Female & 1152 & 255 & & \\
\hline \multicolumn{5}{|c|}{ Literacy } \\
\hline Illiterate & 892 & 219 & \multirow{5}{*}{34.323} & \multirow{5}{*}{$* 0.001$} \\
\hline $\begin{array}{l}\text { Read and } \\
\text { write }\end{array}$ & 75 & 25 & & \\
\hline Gr 1-6 & 835 & 233 & & \\
\hline Gr7-12 & 323 & 37 & & \\
\hline Above 12 & 37 & 0 & & \\
\hline \multicolumn{5}{|c|}{ Income in US dollars } \\
\hline $\begin{array}{c}\text { Below } 200 \text { per } \\
\text { annum }\end{array}$ & 2003 & 505 & \multirow{4}{*}{22.255} & \multirow{4}{*}{$* 0.001$} \\
\hline 201-500 & 154 & 9 & & \\
\hline $501-1000$ & 5 & 0 & & \\
\hline Above 1000 & 0 & 0 & & \\
\hline \multicolumn{5}{|c|}{ House type } \\
\hline Kacha & 1062 & 305 & \multirow{3}{*}{17.578} & \multirow{3}{*}{$* 0.001$} \\
\hline Semi pucca & 1076 & 204 & & \\
\hline Pucca & 24 & 5 & & \\
\hline \multicolumn{5}{|c|}{ Usage of foot wear } \\
\hline Yes & 1820 & 414 & \multirow{2}{*}{4.645} & \multirow{2}{*}{0.81} \\
\hline No & 342 & 100 & & \\
\hline
\end{tabular}

\section{DISCUSSION}

$M$ any studies were conducted in Ethiopia on the prevalence of parasitic diseases with very little emphasis was put on the Epidemiology of tungiasis. In economically backward communities with low socio-economic conditions tungiasis exists as a health problem [1]. This data revealed that the kebeles studied were below the poverty line with inadequate housing and there existed unhygienic life style with inadequate health management. This study shows that highly significant association exist between the prevalence of tungiasis, poor housing and low economic status of the population ( $p$ value $\varangle 0.001$ ). The illiteracy of the studied areas played a significant role in the occurrence of the disease ( $p$ value $\varangle 0.001$ ). The literacy rate of the rural kebeles studied was very poor with $44.18 \%$ illiterates in Wolaita and $38.9 \%$ illiterate people in Jimma. Most of the houses were of kacha or semipucca type with muddy or sandy floorings. The inadequate health care and unhygienic behavior of the population also contributed a significant role in the spreading of the disease $[9,12]$. Close contact with the animals also an important factor in the high prevalence of this disease in the studied area (8). The improper use of foot wear may be one of the reasons for tungiasis infection in this population coupled with lack of appropriate care. This study couldn't reveal the association between usage of foot wear and occurrence of the disease $[6,15]$.

This data reveals that the studied population showed high prevalence of tungiasis. Previous studies indicate that similar to other parasitic diseases, occurrence of severe tungiasis is linked to poverty $[15,17]$. This study shows that the poor communities of studied kebeles of Wolaita and Jimma were like that of Brazil, Trinidad and Nigeria, where there is high prevalence of tungiasis that is $16 \%$ to $54 \%$ ) $[18,19]$.

This study covered a total population of 2676 distributed in eight different kebeles of two distant areas, Wolatia sodo situated in the southern part of Ethiopia and Jimma located in the south western part of Ethiopia. This study also revealed that the occurrence of the disease was closely associated with low economic 
conditions, illiteracy and unhygienic health practices of the community. The study indicates that there was high prevalence of tungiasis among children and elderly. This might be due to poor housing, animal contact, negligence and carelessness. Various statistical data reveals that the study population was below the poverty line.

\section{ACKNOWLEDGEM ENT}

We are expressing our sincere gratitude and indebtedness to Jimma University, Ethiopia for providing the fund and ethical sanction for the project. M oreover, we place on record our whole hearted thanks to the Heads of various kebele and those who have consented for the study.

\section{REFERENCES}

[1]. Heukelbach J, Oliveira FAS, Hesse G, Feldmeier $\mathrm{H}$. Tungiasis: a neglected health problem of poor communities. Trop M ed Int Health 2001;6:267-72

[2]. Gordon RM. The jigger flea. Lancet. 1941;2:47-49.

[3]. Thomas Matenjwa K, Ruth Nyambura N, Zelalem Teka. H, James M W, An exploration of factors assiociated wit jigger infestation (Tungiasis) among residents of M uranga North District, Kenya, International journal of health sciences and research. www.ijhsr.org :ISSN: 2249-9571, 2014.

[4]. Heukelbach J, Oliveira FAS, Hesse G, Feldmeier H. Tungiasis: a neglected health problem of poor communities. Trop Med Int Health.2001;6:267-72.

[5]. Feldmeier $H$, Heukelbach J, Ugbomoiko US, Sentongo E, M babazi P, von Samson-Himmelstjerna G, et al. Tungiasis-A Neglected Disease with Many Challenges for Global Public Health. PLoS Negl Trop Dis 8(10): e3133. doi:10.1371/journal.pntd:2014.

[6]. Eisele M, Heukelbach J, Van M arck E, Mehlhorn H, M eckes $\mathrm{O}$, Franck S, Feldmeier $\mathrm{H}$. Investigations on the biology, epidemiology, pathology and control of Tunga penetrans in Brazil: Natural history of tungiasis in man. Parasitology Research. 2003;90(2):87-99.

[7]. Heukelbach J, Oliveira FAS, Hesse G, Feldmeier H. Tungiasis: A neglected health problem of poor communities. Trop Med Int Health.2001:6:267-72.

[8]. Nair SP, Tsehayneh K, Lemma ZT, Kasssim M, Ramaswamy V. Transmission dynamics of Tungiasis in Ethiopia, World Research Journal of Medical Science, 2013;1(1):7-9.
[9]. Nagy N, Abari E, D'Haese J, Calheiros C, Heukelbach $J$, Menche $\mathrm{N}$, Feldmeier $\mathrm{H}$, Mehlhorn $\mathrm{H}$. Investigations on the Life Cycle and M orphology of Tunga penetrans in Brazil. Parasitology Research. 2007;101(2):233-242.

[10].Muehlen $M$, Feldmeier $H$, Wilcke $T$, Winter $B$, Heukelbach J. Identifying risk factors for tungiasis and heavy infestation in a resource-poor community in northeast Brazil. Transactions of the Royal Society of Tropical Medicine and Hygiene. 2006 Apr 30;100(4):371-80.

[11]. Gordon RM. The jigger flea. Lancet. 1941;2:47-49.

[12]. Heukelbach J, Costa A M , Witcke T, M encka N, Feld meier $\mathrm{H}$. The animal reservoir of Tunga penetrans in severely affected communities of north -east Brazil. Med Vet Entamol. 2004;18:329-335.

[13]. Pampiglione S, Trentini M , Gentilli FM , M endes]LX, Pampiglione C, Rivasi F. Tunga penetrans (Insecta Siphonoptera) in pigs in Sao Tome(Equatorial Africa):Epidemiological, clinical, morphological and histopathological aspects. Revue Elev Med Vet Pays Trop. 1998;51:201-205.

[14]. Ugbomoiko US, Ofoezie IE, Heukelbach]. Tungiasis: High prevalence, parasitic load and morbidity in a rural community in Lagos state, Nigeria.Int J Dermatol. 2007:46:475-481.

[15]. Heukelbach J et al. Tungiasis: a neglected health problem of poor communities. Tropical Medicine and International Health. 2001;6(4)267-272.

[16]. Karunamoorthi. K Tungiasis: a neglected epidermal parasitic skin disease of marginalized populations-a call for global science and policy, Parasitology Research 2013;12(10):3635-3643.

[17]. Heukelbach J, Mencke N, Feldmeir H. Editorial: Cutaneous larva migrans and tungiasis: the challenge to control zoonotic ectoparasitoses associated with poverty. Trop Med Int Health. 2002; 7:907-910.

[18]. Ade Serrano M A, Ejezie GC. Prevalence of tungiasis in Oto Ljanikin village, Badagry, Lagos state, Nigeria.Ann.Trop.M ed.Parasitol.1981;75:471-472.

[19]. Chadee DD. Tungiasis among five communities in south western Trinidad, West Indies. Ann.Trop.Med.Parasitol. 1998;92:107-113.

\section{How to cite this article:}

Suresh Kumar. P. Nair, Zelalem. T. L, Tsehayneh. K, Mehidi. K, Vidhya Ramaswamy V. Assessment of Socioeconomic status and the Prevalence of Tungiasis in Jimma and Wolaita sodo, Ethiopia. Int J Intg Med Sci 2016;3(1):211-215. DOl: 10.16965/ijims.2015.135 